\title{
Alley-cropping system increases vegetation heterogeneity and moderates extreme microclimates in oil palm plantations
}

\begin{abstract}
Forest conversion to oil palm plantation is causing a major loss of biodiversity in Southeast Asia and other tropical regions. Oil palm plantations have less biodiversity because of their simplified vegetation, human disturbances, and extreme microclimate conditions. Alleycropping system incorporates a secondary crop in the alleys between the main crops. In some cases alley-cropping can result in a greater vegetation structural complexity, thus potentially providing agricultural and ecological benefits, including: buffering against weather extremes, reduction in soil erosion, increased biodiversity, and increased nutrient and water-use efficiency. In this study, we compared vegetation structure (height and cover of vegetation), microclimate (air temperature, relative humidity, light intensity and wind speed), and soil conditions (soil surface temperature, soil $\mathrm{pH}$ and soil moisture) across a range of alley-cropping systems and two ages of monoculture oil palm. We found that alley- cropping system had varied structural complexity across different crops when compared to oil palm monoculture system. Careful selection of crops was essential, with black pepper and cacao having the largest impact on improving vegetation heterogeneity and microclimate regulation when incorporated into an alley-cropping system. In particular, we found that systems intercropped with black pepper had air and soil surface temperatures up to $1.3^{\circ} \mathrm{C}$ and $2.1^{\circ} \mathrm{C}$ cooler than those in oil palm monoculture. In contrast, systems intercropped with bactris and bamboo had increased air temperatures. Our findings show that some alley-cropping systems have great potential as a climate-smart practice in sustainable oil palm agriculture. This study also shows that careful selection of crops is important in the planning and management of future alley-cropping system to optimise the ecosystem benefits that can be gained from this management system.
\end{abstract}

Keyword: Agriculture; Biodiversity; Crop; Ecosystem; Monoculture; Sustainable 